\title{
Anesthetic Management for Thoracic Surgery During the COVID-19 Pandemic
}

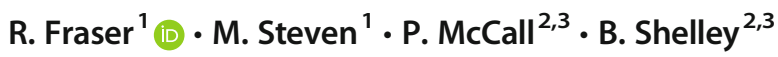

Accepted: 9 June 2021 / Published online: 13 July 2021

(C) Crown 2021

\begin{abstract}
Purpose of Review This review explores recent international guidance on the anesthetic management of patients undergoing thoracic surgery during the COVID-19 pandemic: those with suspected or confirmed COVID-19 requiring urgent thoracic surgery and those presenting for elective procedures.

Recent Findings A significant mortality risk is associated with patients with COVID-19 undergoing thoracic surgery; therefore, where possible, it should be avoided. Thoracic surgery also carries a significant risk of viral transmission to healthcare workers due to the necessarily high frequency of intraoperative aerosol-generating procedures involved, such as lung isolation, one-lung ventilation, and flexible bronchoscopy.

Summary Guidelines recommend appropriate personal protective equipment and numerous procedural modifications to prevent viral transmission to staff and other patients. With appropriate disease mitigation strategies in place, elective thoracic surgery, in particular for lung cancer, has been able to continue safely in many centres.
\end{abstract}

Keywords Anesthesia $\cdot$ Thoracic surgery $\cdot$ COVID-19 $\cdot$ Airway $\cdot$ Lung isolation $\cdot$ One-lung ventilation

\section{Introduction}

Coronavirus disease 2019 (COVID-19) has changed the way we practice medicine worldwide. The specialty of anesthesia and, in particular, thoracic anesthesia has faced major challenges during the crisis due to the frequent necessity to perform aerosol-generating procedures that pose significant risk of viral transmission. The conduct of thoracic anesthesia has duly changed; necessary procedural adaptations to existing techniques, personal protective equipment (PPE), and categorised theatre pathways have been implemented to

This article is part of the Topical Collection on Thoracic Anesthesia

R. Fraser

Rachel.fraser@gjnh.scot.nhs.uk

1 Cardiothoracic Anaesthesia, Golden Jubilee National Hospital, Agamemnon Street, Clydebank, Glasgow G81 4DY, UK

2 Cardiothoracic Anaesthesia and Intensive Care, Golden Jubilee National Hospital, Glasgow, UK

3 Critical Care and Peri-operative Medicine Research Group, University of Glasgow, Glasgow, UK minimise nosocomial transmission and keep patients and healthcare workers safe. In addition to the clinical challenge of caring for patients with COVID-19, the global disease burden and strain on healthcare resources have had a detrimental impact on the management of patients with other thoracic conditions, namely delays in diagnosis and surgical treatment of lung cancer.

We aim to provide a comprehensive and up-to-date review of the literature relating to anesthetic management for thoracic surgery during the COVID-19 crisis. We conducted a search of the major electronic databases, PubMed and MEDLINE, without language restriction using keywords COVID-19, anesthesia, thoracic anesthesia, lung isolation, and one-lung ventilation up to May 2021 with particular focus on literature containing national guidance and consensus recommendations. We also include expert opinion from our own highvolume thoracic centre and any other references or resource of which we were aware.

\section{The COVID-19 Pandemic}

The World Health Organisation declared the outbreak of severe acute respiratory syndrome coronavirus-type 2 (SARS- 
CoV-2) causing COVID-19 a pandemic, on March 11, 2020 [1]. The disease emerged in the preceding December in China's Wuhan province and subsequently demonstrated rapid global spread via human-to-human transmission. It has since caused mass fatalities and had an unprecedented deleterious impact on global health systems.

Current epidemiological reports indicate that viral transmission is generated from release of virus-containing respiratory droplets or particles during normal exhalation, and actions such as; speaking, coughing, and sneezing, from an infected person [2]. Exposure to viral droplets occurs through direct contact with mucous membranes or inhalation of aerosolised airborne particles, which are smaller particles that can remain suspended in the air for a longer duration and travel further distances than larger respiratory droplets [2].

\section{Aerosol-Generating Procedures}

Aerosolised particles are defined as being less than $5 \mu \mathrm{m}$ in size [3]. The typical diameter of SARS-CoV-2 is $0.1 \mu \mathrm{m}$ [4]; therefore, it can aerosolise, remain airborne indefinitely in poorly ventilated areas, and be easily inhaled into the lower respiratory tract [3]. Many procedures involved in airway management such as manual facemask ventilation and tracheal intubation and extubation have the potential to release aerosols from the patient's respiratory tract $[5,6]$ and are widely known as aerosol-generating procedures (AGPs), which pose a significant concern to healthcare workers. Some guidelines distinguish between vulnerable AGPs which occur in the absence of gas flow and true AGPs that involve gas flow, especially flows of high velocity [7]. There remains, however, some debate over what constitutes an AGP. Brown and colleagues demonstrated that controlled tracheal intubation in a paralysed patient produced significantly less aerosol than a volitional cough and, therefore, did not support elective tracheal intubation being a "designated AGP" [8]. It continues to be deemed an AGP; however, it can be deduced from this work that performing airway procedures during patient apnoea with complete neuromuscular blockade would remove much of the potential for active gas flow, therefore minimising the risk of aerosol generation.

\section{Aerosol Generation in Thoracic Surgery}

Thoracic surgery, unlike many other surgeries, risks high levels of COVID-19 aerosolisation into the theatre environment. This is largely attributed to disturbed virus-rich tissues from airway and pulmonary surgical procedures, as well as the necessary and frequent performance of intraoperative AGPs that are integral to routine thoracic anesthesia (Table 1). Healthcare workers involved in the intraoperative
Table 1 Sources of potential aerosolisation in thoracic surgery

Manual facemask ventilation

Tracheal intubation

Tracheal extubation

Tracheal tube manipulation

Respiratory tract suctioning (without closed in-line system)

Bronchoscopy (rigid and flexible)

Jet ventilation

Lung isolation and one-lung ventilation (with operative lung open to atmosphere)

Oxygen insufflation to operative lung through suction catheter

Continuous positive airway pressure application to operative lung

Disconnection of active ventilatory circuit

Insertion of tracheostomy/mini-tracheostomy

Intrathoracic carbon dioxide insufflation during thoracoscopic surgery

Parenchymal lung breach or air leak

Chest drain management

management of thoracic surgical patients with COVID-19 infection are therefore at significant risk of virus exposure.

\section{Thoracic Surgery During the COVID-19 Pandemic}

\section{COVID-19-Related Thoracic Surgery}

Urgent thoracic surgical intervention may be required for a minority of patients with severe COVID-19 disease. Invasively ventilated patients are at increased risk of barotrauma due to prolonged positive pressure ventilation of diseased and fibrotic lungs compared to patients with non-COVID-19-related acute respiratory distress syndrome (ARDS). McGuinness and colleagues reported barotrauma (pneumothorax or pneumomediastinum) in 15\% of COVID-19 patients on invasive mechanical ventilation compared to $10 \%$ of ventilated patients with conventional ARDS in their institution [9]. Persistent air leak management may require surgical management if initial treatments fail. Surgical management of pleural empyema as a complication of severe COVID-19 has also been reported [10], and, rarely, lung transplantation as salvage therapy for irreversible lung damage in carefully selected COVID-19 patients [11].

\section{Elective Thoracic Surgery}

It is well documented that undergoing surgery with perioperative SARS-CoV-2 infection carries significant risks [12•, 13, 14]. A large international multicentre cohort study 
demonstrated postoperative pulmonary complications in more than half of all surgical patients with SARS-CoV-2 infection and a $23.8 \%$ mortality rate at 30 days [12•]. Therefore, wherever possible, patients who test positive for SARS-CoV-2 or fail part of the preoperative screening process should have their elective surgery delayed. Another landmark international study recently demonstrated an increased morbidity and mortality risk if patients underwent surgery within 6 weeks of a COVID-19 diagnosis and therefore recommended that surgery should be delayed, where possible, for at least 7 weeks following diagnosis, and longer for patients with ongoing symptoms [15•].

Throughout the pandemic, management of COVID-19 patients has been balanced with the need to manage those with other life-threatening diseases such as lung cancer. Lung cancer commonly has overlapping symptoms with COVID-19 disease, which has led to delayed cancer presentation and, in conjunction with reduced healthcare services and fear of accessing them, delayed diagnosis and treatment. Overall lung cancer deaths up to 5 years after diagnosis are predicted to increase by 5\% in England [16]. Depending on geographical area and local prevalence of COVID-19 infection, elective lung cancer surgery services have been reduced or postponed in many areas.

Where possible, surgery for lung cancer should avoid lengthy delays and remain a clinical priority, forcing surgeons to prioritise among their cancer patients according to published guidelines $[17,18]$. To this end, low-risk or COVID19-free surgical pathways are recommended to ensure that patients presenting for elective cancer surgery during the pandemic are safe from nosocomial transmission [19]. Guidelines concur that high-risk or COVID-19 patients should be separated from low-risk patients and that patient groups should be managed in designated areas with established hospital protocols in place for patient transport, workflows, and theatre management [12•, 19-22]. The first essential component in maintaining a safe perioperative pathway is institution of sufficient preoperative COVID-19 screening and reverse transcription polymerase chain reaction (RT-PCR) testing for all patients to ensure, as much as possible, they are not already infected.

In healthcare settings, the type of PPE required for staff varies depending on local guidelines and is usually classified into contact, droplet, and airborne/aerosol precautions [23]. As thoracic surgery carries a high risk of aerosolisation, the use of aerosol precaution PPE by theatre staff throughout the case is recommended if the patient's COVID-19 status is unknown, suspected, or confirmed positive. In settings where an AGP has been performed and there is no further risk of planned or unplanned AGP, e.g., tracheal extubation, downgrading of PPE to droplet precautions is recommended only after a certain duration of time has passed. This duration is multifactorial and is based on location, theatre air pressure, and rate of airflow. Negative-pressure theatres with high rates of air exchange (> 12 air changes/min) are preferable as airborne particles are cleared quicker [24]. Specific details on the components of PPE and environmental factors associated with viral transmission following AGPs are beyond the scope of this review and are covered extensively elsewhere [22,23].

\section{Conduct of Anesthesia}

Continuation of lung cancer surgical services as well as management of COVID-19 patients during the evolving pandemic presents many challenges, and a need for guidance in this subspecialty group was identified. Society-endorsed recommendations and guidelines from around the world have been produced to aid anesthetic management of patients undergoing thoracic surgery during the pandemic [25•, 26•, 27-31]. By necessity, they have generally been formed from collective expert opinion in the absence of available evidence-based data.

In the management of all COVID-19 patients undergoing anesthesia, it is widely acknowledged that the minimum number of staff should be present in theatre during intubation and other AGPs and that these should be performed by the most experienced operator to maximise efficiency and minimise aerosol generation $[32,33]$. This applies even more so in the practice of thoracic anesthesia as correct placement of lungisolating airway devices and the use of bronchoscopy and onelung ventilation are highly technical skills, best performed by an anesthetist familiar with thoracic surgery. Disposable equipment should be used where possible, and detailed team briefings should be held with a focus on AGP management.

Many endorsed techniques to reduce aerosol generation during induction of general anesthesia and intubation also apply to thoracic patients: thorough preoxygenation, avoidance of high gas flows, avoidance of manual facemask ventilation, use of two-handed face mask technique when necessary, rapid sequence induction, ensuring complete neuromuscular blockade prior to airway instrumentation, use of videolaryngoscopy, and tracheal tube cuff inflation prior to ventilation $[24,32,33]$.

\section{Lung Isolation}

Lung isolation enables each lung to be ventilated independently. The primary function in thoracic surgery is to facilitate deflation of the operative lung and thereby maximise surgical exposure. The most widely used device for enabling lung isolation is a double lumen tube (DLT). Most published literature regarding lung isolation during the pandemic focuses on recommendations for DLT use [25•, 27, 29-31]. Other options include bronchial blockers and, rarely, single lumen tubes advanced into the bronchus of the non-operative lung. 
In our opinion, the DLT provides the most efficient method for lung isolation as they are quicker to site (left more so than right) and are more likely to be positioned correctly compared with bronchial blockers [34•]. There is also a higher incidence of intraoperative bronchial blocker dislocation after initial placement [35]. DLTs allow differential ventilation, better access to the airway for suctioning, and easier application of continuous positive airway pressure (CPAP) to the operative lung, whereas bronchial blockers prevent bronchoscopic access and limit suction to the operative lung during lung isolation [25•].

There are, however, certain circumstances where the use of a bronchial blocker with an already sited single lumen tube might be preferred over exchanging it for a DLT. It may be best to avoid airway device exchange in patients who are already intubated and those requiring continued postoperative mechanical ventilation $\left[25^{\bullet}, 26^{\bullet}\right]$. Airway manipulation and device exchange in critically hypoxic patients can be poorly tolerated, and the risk of aerosol generation is increased during this time. As before the pandemic, intubation with a single lumen tube and use of a bronchial blocker may also be a better option for patients with predicted difficult airways or those requiring awake fibre optic intubation [26•, 27, 29].

Bronchial intubation of the non-operative lung with a single lumen tube can achieve rapid lung isolation with little airway manipulation; however, gas from the operative lung will be freely expelled on passive lung deflation, unavoidably contaminating the atmosphere. Additionally, the distance between the tip and cuff of a standard single lumen tube may exceed the length of some main bronchi, and therefore, a cuff above the carina will fail to provide lung isolation. It may also occlude and fail to ventilate the right upper lobe when sited in the right main bronchus.

Overall, there is a lack of comparative data, and no single device has been advocated as being superior in the mitigation of aerosols. We recommend that choosing the most suitable device for lung isolation during the pandemic should be patient-specific and perhaps most importantly based on methods familiar to the anesthetist with adaptations to limit aerosol generation.

\section{Airway Device Positioning}

\section{Flexible Bronchoscopy}

Flexible bronchoscopy is routinely used to guide and confirm the correct positioning of DLTs and bronchial blockers prior to initiation of one-lung ventilation; however, the bronchoscope is normally introduced through a port which is not airtight and therefore risks considerable aerosol generation during ventilation. There is conflicting advice among societies regarding the use of bronchoscopy in this context. Regarding DLT placement, some societies advocate clinical confirmation of DLT position suggesting that bronchoscopy should be reserved for encountering difficulty or troubleshooting tube misplacement $[27,28]$, whereas the majority still advocates the use of bronchoscopy in all patients $\left[25^{\bullet}, 26^{\bullet}\right.$, $29,31,36]$, as it is the most reliable method of device placement. Guidelines concur that it should only be performed; during gas flow cessation, patient apnoea, without positive pressure in the circuit, and the adjustable pressure-limiting (APL) valve set at zero $\mathrm{cmH}_{2} \mathrm{O}$. A peripheral nerve stimulator is recommended to confirm deep neuromuscular blockade, thereby preventing inadvertent coughing and aerosolisation during instrumentation of the airway $\left[24,26^{\bullet}\right]$.

Prior to introducing the bronchoscope, endorsed procedural modifications include the use of anti-viral airway filters to mitigate aerosolisation $[25 \bullet, 26 \bullet, 27-31]$. Anti-viral filters should be applied to any open lumen of an airway device when disconnected from the ventilatory circuit. This should be done under apnoeic conditions without positive pressure in the circuit and with the use of clamps to first safely isolate the disconnection point. Clamps can be applied to the DLT lumen and corresponding catheter mount arm before disconnection; the anti-viral filter is then attached to the DLT lumen. The DLT lumen clamp can then be removed allowing the lung to passively deflate through the filter, preventing environmental contamination [25•]. Alternatively, anti-viral filters can be attached to the DLT catheter mounts prior to intubation (Fig. 1a), meaning only the catheter mount requires clamping (Fig. 1b) prior to disconnection (Fig. 1c). The filter is subsequently removed and the bronchoscope introduced into the DLT lumen (Fig. 1d). This process may be repeated for the contralateral DLT lumen if required. The bronchoscope should be kept in a designated area and ideally used by a single operator with appropriate hygiene steps following each use [25•]. Disposable single-use bronchoscopes are also recommended if available $[27,29]$. Other described adaptations to reduce aerosol generation during bronchoscopy include the use of a clear sterile laparoscopic camera cord cover that acts as a closed barrier sheath by enclosing the bronchoscope proximally and distally at the airway device connection [37]. Flexible bronchoscopy is also consistently recommended whilst troubleshooting incorrect tracheal tube placement. The tracheal cuff can remain inflated during repositioning to prevent a leak and aerosol generation; it also avoids inadvertent extubation by preventing the tube exiting at the level of the vocal cords if withdrawing the DLT under bronchoscopic guidance [25•].

\section{Avoidance of Flexible Bronchoscopy}

Concern over the risk of atmospheric contamination from an open airway required for introduction of the bronchoscope has led some authors to recommend avoidance of bronchoscopy 

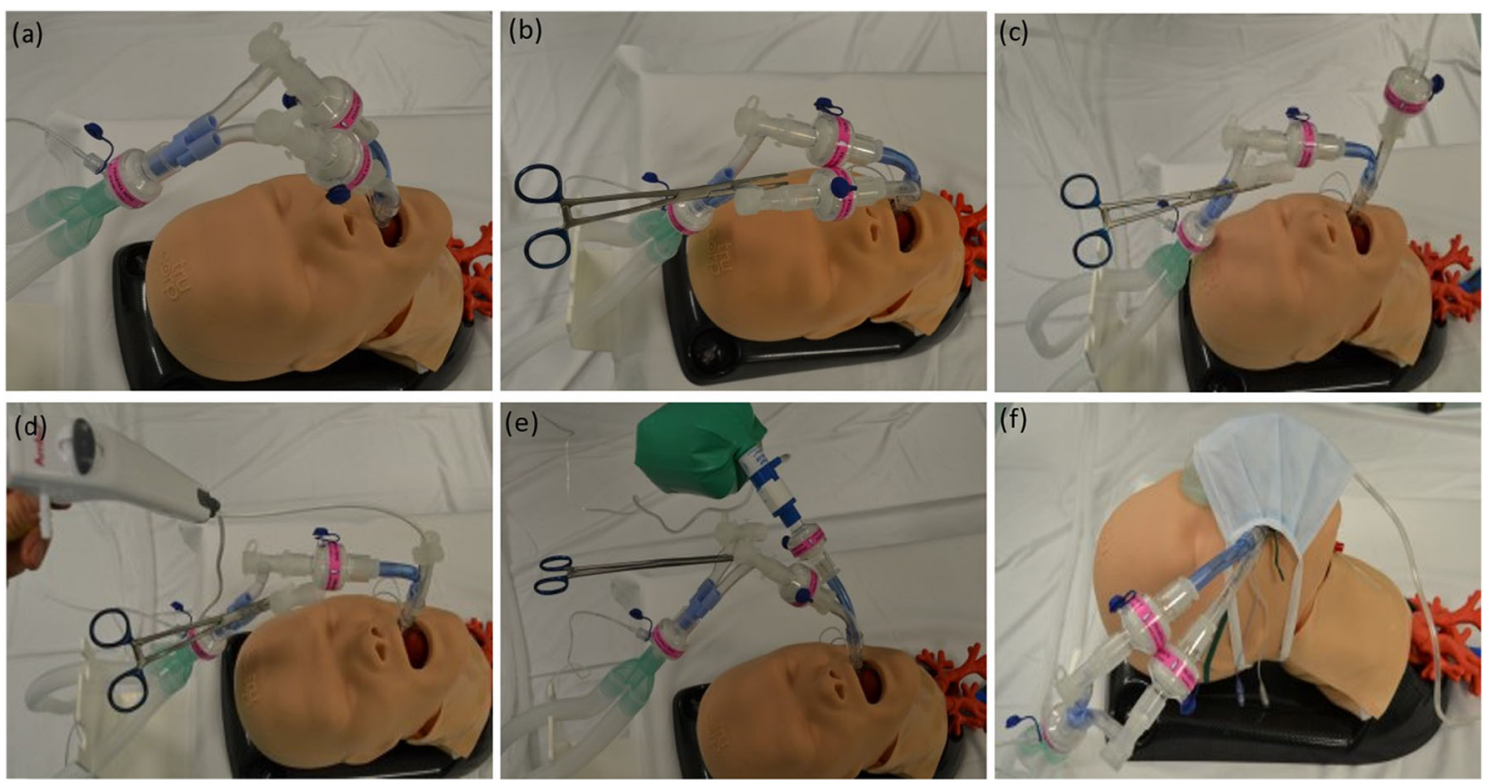

Fig. 1 Risk mitigation and avoidance of aerosolisation in DLT management. Manikin images demonstrating (a) paediatric HME filters on both DLT lumens and between the catheter mount and ventilatory circuit; (b) clamp applied to the surgical catheter mount lumen; (c) disconnection between the catheter mount and HME filter allowing passive lung deflation through the filter during apnoea; (d) removal of HME filter for passage of the flexible bronchoscope; (e) addition of CPAP circuit to the operative lung through a HME filter; and (f) extubation of a DLT to the side of an oxygen mask covered by fluidresistant surgical facemask by advocating alternative methods of device placement confirmation. This includes a clinical check of DLT placement with chest auscultation and sequential clamping of the tracheal and bronchial arms without disconnection [27, 28, 38]. It has been well documented, however, that around a third of clinically verified DLT placements are still unsatisfactory and require bronchoscopy for correct repositioning [39]. Furthermore, if tube misplacement is not initially diagnosed and part of the operative lung is ventilating during surgical opening, there is a significant risk of lung injury and environmental contamination. We suggest, therefore, that with appropriate risk mitigation, it is still preferable to use bronchoscopic guidance in the first instance to avoid later repositioning and risks of atmospheric contamination if malpositioned.

DLTs with in-built carinal cameras (e.g., Vivasight ${ }^{\mathrm{TM}}$, Ambu) can also be sited without bronchoscopy; however, the static camera position does not allow visualisation of more distal bronchial anatomy which can be problematic in cases of lobar intubation. Additionally, the use of the integrated flushing port to clear secretions from the camera carries a risk of aerosol generation [40].

Bronchial blocker placement typically requires bronchoscopic guidance. Senturk and colleagues have suggested the use of an EZ blocker if a bronchoscope is unavailable [26 ${ }^{\bullet}$; however, this is contraindicated by the manufacturer [41], and other authors have described the mandatory use of bronchoscopy with this device [42].

Lastly, it has been suggested that point-of-care lung ultrasound can confirm lung isolation by identifying lung sliding during ventilation in the non-operative lung and absence of lung sliding and lung pulse without ventilation in the operative lung $[27,29]$. This technique has been shown to be superior to auscultation alone in confirming lung isolation $[43,44]$; however, it may be unreliable in the context of COPD and pleural disease, and it cannot be used to inform re-positioning of malpositioned devices [44]. Moreover, it is not widely used in practice, and we recommend that anesthetists should use familiar techniques and equipment in the management of COVID-19 patients to avoid any increased risk of failure and contamination.

\section{One-Lung Ventilation}

One-lung ventilation is traditionally achieved by allowing the operative lung to passively deflate and release alveolar gas through an open lumen to the atmosphere whilst maintaining ventilation of the non-operative lung. Clearly, this method risks unacceptable aerosolisation and contamination of the theatre environment. To mitigate this risk, all related guidelines recommend lung deflation through an anti-viral filter. One-lung ventilation should be initiated prior to surgical incision to reduce the risk of lung parenchymal injury and resultant air leak. Application of suction to the operative lung to expedite collapse may be considered; however, it can generate unnecessary aerosols if an open-suction technique is used; hence, some societies have advised against it [26•,27]. Other suggested adaptations for safe lung deflation include 
the use of a laparoscopy smoke evacuation system which is connected to the distal end of the airway device and contains an ultra-low particulate air (ULPA) filter to trap pathogens and prevent aerosolisation [45].

To date, there are no clinical studies specifically investigating one-lung ventilation strategies in COVID-19 patients. Recommendations for one-lung ventilation in patients with COVID-19 are in keeping with those for any patient on onelung ventilation and include lung-protective tidal volumes (4$6 \mathrm{~mL} / \mathrm{kg}$ predicted body weight), permissive hypercapnia, and titrated application of positive end expiratory pressure (PEEP) [26•]. Normal practice in the management of shunt-driven hypoxemia during one-lung ventilation includes oxygen insufflation or application of CPAP to the operative lung. CPAP with the addition of an anti-viral filter is a recommended strategy in suspected or confirmed COVID-19 patients (Fig. 1e) [25•, 28]; this avoids aerosol release from the airway but may cause a persistent air leak into the operative field through any parenchymal breach, exposing the operative staff to aerosolisation. There are reports of safe one-lung ventilation in patients with COVID-19 lung disease [46]; however, it might be expected that OLV would be challenging in patients with severe lung disease and may result in intolerable hypoxemia or hypercapnia [26*]. Van den Eynde and colleagues advise against one-lung ventilation in all patients with COVID-19 diseased lungs due to these risks [47]. Furthermore, even if tolerated, one-lung ventilation may worsen respiratory function in COVID-19 patients; the potential for lung injury following one-lung ventilation is well recognised, even in normal lungs [48]. One-lung ventilation should be abandoned in patients with critical hypoxemia. If CPAP fails to improve oxygenation, pausing surgery and reverting to intermittent two-lung ventilation is the conventional approach. Low tidal volume two-lung ventilation may be feasible for some procedures [49]. Extracorporeal life support techniques may facilitate necessary surgery in carefully selected patients [26•].

\section{Airway Filters}

Recommended anti-viral filters include high-efficiency particulate air (HEPA) or heat and moisture exchange (HME) filters. Both have been shown to capture viral particles of a similar size to SARS-CoV-2; however, there has been no direct studies investigating this thus far $[50,51]$. Smaller paediatric HME filters can be used without increasing airway resistance [51] and may be easier to manage with less risk of tube kinking [28]. These are also small enough to be attached, sideby-side, to both DLT lumens immediately after intubation (Fig. 1a) [37]. Filters should also be applied between the facemask and ventilatory circuit as well as on the expiratory limb connection with the anesthetic machine. Some may also apply a filter to the inspiratory limb to eliminate any chance of error if only using one limb filter [52,53].

Regarding bronchial blockers, Hargrave and colleagues describe the successful addition of various adaptors to the proximal end of bronchial blockers to allow connection to antiviral filters (e.g., a CPAP adaptor for an Arndt bronchial blocker and a $3.0-\mathrm{mm}$ endotracheal tube $15 \mathrm{~mm}$ connector for a 9.0 French Fuji uniblocker) [54]. Theoretically, this minimises the risk of environmental contamination from the airway and allows application of CPAP to the operative lung if required. The passage of the blocker through the multiport adaptor must be secured to ensure the system is airtight.

\section{Suctioning}

Respiratory tract and tracheal tube suctioning are frequently required during thoracic surgical procedures. Removal of respiratory secretions using a closed in-line suction system attached to the operative limb of the DLT or single lumen tube avoids circuit disconnection and aerosol generation [26•, 27, 28]. It is a blind technique, however, that may be inadequate for problematic secretions and may risk mucosal injury. The length of suction catheter required to reach distal bronchial airways also needs to be considered. Otherwise, standard suction catheters or suction under bronchoscopic guidance can be used. As with any instrumentation of an open airway, the patient should be apnoeic with complete neuromuscular blockade and without positive pressure in the ventilatory circuit. Surgical manipulation should be avoided during this time to prevent any gas flow in the circuit risking aerosolisation. Used suction catheters should be placed in designated areas or discarded after single use to avoid contamination. In general, the number of suctioning events throughout the procedure should be minimised if possible [30, 31].

\section{Lung Re-expansion}

Lung re-expansion with positive pressure at the end of surgery is another procedure that carries a risk of aerosolisation if the lung parenchyma is breached, causing an alveolar air leak. In addition to tissue sealants used by the surgeon, limiting positive pressure can reduce strain on staple lines and reduce potential air leak. It is also worth considering that COVID-19damaged lung tissue may not re-expand as expected, as noted by Bellini and colleagues [46]. Another suggested, but not widely endorsed, method of lung re-expansion is moderate chest drain suction to provide intrathoracic negative pressure under thoracoscopic guidance after surgical closure [31]. The remaining camera incision can then be closed and ventilation resumed. 


\section{Extubation}

The risk of aerosolisation during extubation is high due to the potential for coughing, particularly with a large DLTs compared to smaller diameter single lumen tubes. The oropharynx should be cleared of secretions prior to reversal of neuromuscular blockade, and suctioning of the tracheal tube at the point of extubation should be avoided as it may precipitate coughing [25•]. Antitussive drugs such as opioids and dexmedetomidine can be used to reduce the risk of coughing [24]. Awake extubation with the patient spontaneously breathing may be preferred over deep extubation, which carries an increased risk of airway complications which in turn risks the need for further AGPs [40]. Extubation under large clear plastic drapes to limit aerosolisation spread has previously been described [27]. An oxygen mask may be placed on the patient's face prior to extubation (Fig. 1f). As the DLT is removed to the side of the oxygen mask, the mask traps respiratory droplets and potentially reduces aerosol spread. A surgical face mask placed over the oxygen mask to cover the air entrainment slits may further reduce aerosol dispersion.

\section{Chest Drainage}

Many thoracic surgical patients have the requirement for intercostal chest drainage which is connected to a drainage system in the immediate postoperative period. A bubbling chest drain with an ambient air exhaust can generate aerosols [55]. The British Thoracic Society suggests mitigating this risk by constant connection of chest drains to wall suction, use of a digital chest drain system, or use of an anti-viral filter attached to a standard chest drainage system [56]. Duffy and colleagues subsequently confirmed effective aerosolisation prevention with the use of the anti-viral filter in this context [57].

\section{Anesthetic Considerations for Recovered COVID-19 Patients}

It is well known that a subset of patients who have recovered from severe COVID-19 disease suffer with long-lasting clinical sequelae involving multiple organ systems including residual cardiorespiratory dysfunction. This is likely to influence future medical care that these patients may require. Recent studies have described patients with residual respiratory dysfunction mainly resulting from restrictive lung damage. A meta-analysis by Ahmed and colleagues reported impaired diffusing capacity for carbon monoxide (DLCO) in 15$45 \%$ of patients up to 6 months after hospital discharge [58]. This correlates with commonly reported persistent radiological abnormalities such as interstitial thickening and fibrosis on follow-up CT scans following discharge [59]. One-lung ventilation may be poorly tolerated in this patient group if presenting for subsequent thoracic surgery, though as yet experience is limited. Further studies on long-term outcomes in recovered severe COVID-19 patients will be beneficial in the management of this patient population.

\section{Conclusion}

We have reviewed and consolidated current international expert opinion and consensus recommendations to provide a collective platform of guidance specific to thoracic anesthetic management during the COVID-19 pandemic. It is important that thoracic centres develop and use protocols based on the best available guidance to perform aerosol-generating procedures diligently, thereby reducing the risk of aerosol transmission and protecting patients and healthcare workers involved in these procedures. Due to the rapidly evolving nature of the pandemic, continued re-evaluation of recommendations for the anesthetic management of thoracic surgical patients is needed.

\section{Declarations}

Human and Animal Rights This article does not contain any studies with human or animal subjects performed by any of the authors.

Conflict of Interest The authors declare no competing interests.

\section{References}

Papers of particular interest, published recently, have been highlighted as:

- Of importance

1. World Health Organization. Novel coronavirus (2019-nCoV) situation report. https://www.who.int/emergencies/diseases/novel-coronavirus-2019/situation-reports. (accessed 11/04/21)

2. Centers for Disease Control and Prevention. Scientific brief: SARSCoV-2 transmission. https://www.cdc.gov/coronavirus/2019-ncov/ science/science-briefs/sars-cov-2-transmission.html (accessed 10/ $05 / 21$ )

3. Fennelly KP. Particle sizes of infectious aerosols: implications for infection control. Lancet Respir Med. 2020;8(9):914-24. https:// doi.org/10.1016/S2213-2600(20)30323-4.

4. Machhi J, Herskovitz J, Senan AM, Dutta D, Nath B, Oleynikov MD, et al. Kevadiya BD The natural history, pathobiology, and clinical manifestations of SARS-CoV-2 infections. J NeuroImmune Pharmacol. 2020;15(3):359-86. https://doi.org/10. 1007/s11481-020-09944-5.

5. NHS National Services Scotland and Health Protection Scotland. Aerosol generating procedures (AGPs). 2020. https:// hpspubsrepo.blob.core.windows.net/hpswebsite/nss/2893/documents/ 1_tbp-lr-agp.pdf (accessed 11/04/21)

6. Tran K, Cimon K, Severn M, Pessoa-Silva CL, Conly J. Aerosol generating procedures and risk of transmission of acute respiratory 
infections to healthcare workers: a systematic review. PLoS One. 2012;7:e35797. https://doi.org/10.1371/journal.pone.0035797.

7. Brewster DJ, Chrimes N, Do TB, et al. Consensus statement: safe airway society principles of airway management and tracheal intubation specific to the COVID-19 adult patient group [published correction appears in Med J Aust. 2020 Oct;213(7):312]. Med J Aust. 2020;212(10):472-81. https://doi.org/10.5694/mja2.50598.

8. Brown J, Gregson FKA, Shrimpton A, Cook TM, Bzdek BR, Reid JP. Pickering AE A quantitative evaluation of aerosol generation during tracheal intubation and extubation. Anaesthesia. 2021;76(2): 174-81. https://doi.org/10.1111/anae.15292.

9. McGuinness G, Zhan C, Rosenberg N, Azour L, Wickstrom M, Mason DM, et al. Moore WH Increased incidence of barotrauma in patients with COVID-19 on invasive mechanical ventilation. Radiology. 2020;297(2):E252-62. https://doi.org/10.1148/radiol. 2020202352.

10. Tessitore A, Patella M, Giuliani M, et al. Surgical treatment of pleural empyema in coronavirus disease 19 patients: the Southern Switzerland experience [published online ahead of print, 2020 Nov 22]. Interact Cardiovasc Thorac Surg. 2020;ivaa269. https:// doi.org/10.1093/icvts/ivaa269

11. Lang C, Jaksch P, Hoda MA, Lang G, Staudinger T, Tschernko E, et al. Schellongowski P Lung transplantation for COVID-19associated acute respiratory distress syndrome in a PCR-positive patient. Lancet Respir Med. 2020;8(10):1057-60. https://doi.org/ 10.1016/S2213-2600(20)30361-1.

12. COVIDSurg Collaborative. mortality and pulmonary complications in patients undergoing surgery with perioperative SARSCoV-2 infection: an international cohort study. Lancet. 2020;396(10243):27-38. https://doi.org/10.1016/S0140-6736(20) 31182-X.12 An international study demonstrating the significantly increased morbidity and mortality in patients undergoing surgery with perioperative SARS-CoV-2.

13. Lei S, Jiang F, Su W, Chen C, Chen J, Mei W, et al. Xia Z Clinical characteristics and outcomes of patients undergoing surgeries during the incubation period of COVID-19 infection. EClinicalMedicine. 2020;21:100331. https://doi.org/10.1016/j. eclinm.2020.100331.

14. Doglietto F, Vezzoli M, Gheza F, Lussardi GL, Domenicucci M, Vecchiarelli L, et al. Fontanella MM Factors associated with surgical mortality and complications among patients with and without Coronavirus disease 2019 (COVID-19) in Italy. JAMA Surg. 2020;155(8):1-14. https://doi.org/10.1001/jamasurg.2020.2713.

15. COVIDSurg Collaborative. GlobalSurg Collaborative. Timing of surgery following SARS-CoV-2 infection: an international prospective cohort study. [published online ahead of print, 2021 Mar 9]. Anaesthesia. 2021. https://doi.org/10.1111/anae.15458 A landmark international study recommending at least 7 weeks delay for surgery in patients with a pre-operative SARS-CoV-2 diagnosis due to the increased mortality demonstrated in patients undergoing surgery within 6 weeks following SARS-CoV-2 infection.

16. Maringe C, Spicer J, Morris M, Purushotham A, Nolte E, Sullivan $\mathrm{R}$, et al. The impact of the COVID-19 pandemic on cancer deaths due to delays in diagnosis in England, UK: a national, populationbased, modelling study [published correction appears in Lancet Oncol. 2021 Jan;22(1):e5]. Lancet Oncol. 2020;21(8):1023-34. https://doi.org/10.1016/S1470-2045(20)30388-0.

17. Jheon S, Ahmed AD, Fang VW, Jung W, Khan AZ, Lee JM, et al. Thoracic cancer surgery during the COVID-19 pandemic: a consensus statement from the thoracic domain of the Asian society for cardiovascular and thoracic surgery. Asian Cardiovasc Thorac Ann. 2020 Jul;28(6):322-9. https://doi.org/10.1177/0218492320940162.

18. Thoracic Surgery Outcomes Research Network, Inc, Antonoff M, Backhus L, et al. COVID-19 guidance for triage of operations for thoracic malignancies: a consensus statement from thoracic surgery outcomes research network. Ann Thorac Surg. 2020;110(2):692-6. https://doi.org/10.1016/j.athoracsur.2020.03.005.

19. Glasbey JC, Nepogodiev D, Simoes JFF. Elective cancer surgery in COVID-19-free surgical pathways during the SARS-CoV-2 pandemic: an international, multicenter, comparative cohort study. J Clin Oncol. 2021;39(1):66-78. https://doi.org/10.1200/JCO.20.01933.

20. Wax RS, Christian MD. Practical recommendations for critical care and anesthesiology teams caring for novel coronavirus (2019nCoV) patients. Can J Anesth. 2020;67(5):568-76. https://doi.org/ 10.1007/s12630-020-01591-x.

21. Flemming S, Hankir M, Ernestus RI, Seyfried F, Germer CT, Meybohm P, et al. Wiegering A Surgery in times of COVID-19recommendations for hospital and patient management. Langenbeck's Arch Surg. 2020;405(3):359-64. https://doi.org/10. 1007/s00423-020-01888-x.

22. Public Health England. COVID-19 infection prevention and control guidance. https://assets.publishing.service.gov.uk/government/uploads/system/uploads/attachment data/file/954690/ Infection_Prevention_and_Control_Guidance_January_2021.pdf (accessed 11/04/21)

23. Centers for Disease Control and Prevention. Infection control guidance for healthcare professionals about coronavirus (COVID-19). https://www.cdc.gov/coronavirus/2019-ncov/hcp/infectioncontrol.html (accessed 11/04/21)

24. Cook TM, El-Boghdadly K, McGuire B, McNarry AF, Patel A, Higgs A. Consensus guidelines for managing the airway in patients with COVID-19: guidelines from the Difficult Airway Society, the Association of Anaesthetists the Intensive Care Society, the Faculty of Intensive Care Medicine and the Royal College of Anaesthetists. Anaesthesia. 2020 Jun;75(6):785-99. https://doi.org/10.1111/anae. 15054.

25. Thornton M, Reid D, Shelley B, Steven M. Management of the airway and lung isolation for thoracic surgery during the COVID19 pandemic: recommendations for clinical practice endorsed by the Association for Cardiothoracic Anaesthesia and Critical Care and the Society for Cardiothoracic Surgery in Great Britain and Ireland. Anaesthesia. 2020;75(11):1509-16. https://doi.org/10. 1111/anae.15112.25 Thorough review of airway management in thoracic anesthesia during the pandemic with societyendorsed practice-based recommendations.

26. S S Sentürk M, El Tahan MR, Szegedi LL, et al. Thoracic anesthesia of patients with suspected or confirmed 2019 novel coronavirus infection: preliminary recommendations for airway management by the European Association of Cardiothoracic Anaesthesiology Thoracic Subspecialty Committee. J Cardiothorac Vasc Anesth. 2020;34(9): 2315-27. https://doi.org/10.1053/j.jvca.2020.03.059.26 Societyendorsed recommendations from an extensive international survey of experts in thoracic anesthesia.

27. Fiorelli S, Menna C, Piccioni F, Ibrahim M, Rendina EA, Rocco M, et al. The cutting edge of thoracic anesthesia during the Coronavirus disease 2019 (COVID-19) outbreak. J Cardiothorac Vasc Anesth. 2020;34(12):3203-10. https://doi.org/10.1053/j.jvca.2020.05.042.

28. Irons JF, Pavey W, Bennetts JS, Granger E, Tutungi E, Almeida A. COVID-19 safety: aerosol-generating procedures and cardiothoracic surgery and anesthesia - Australian and New Zealand consensus statement. Med J Aust. 2021;214(1):40-4. https://doi.org/10.5694/mja2.50804.

29. Shaylor R, Verenkin V, Matot I. Anesthesia for patients undergoing anesthesia for elective thoracic surgery during the COVID-19 pandemic: a consensus statement from the Israeli Society of Anesthesiologists. J Cardiothorac Vasc Anesth. 2020;34(12): 3211-7. https://doi.org/10.1053/j.jvca.2020.07.049.

30. Singh A, Iyer KV, Roy A, Khanna P. One lung ventilation during COVID-19 pandemic. Trends Anesth Crit Care. 2020;33:30-2. https://doi.org/10.1016/j.tacc.2020.06.005.

31. Rakovich G, Urbanowicz R, Issa R, Wang HT. Minimising the risk of aerosol contamination during elective lung resection surgery. 
Ann Surg. 2020;272:e125-8. https://doi.org/10.1097/SLA. 0000000000004087.

32. World Federation of Societies of Anesthesiologists (WFSA). Coronavirus - guidance for anesthesia and perioperative care providers. https://www.wfsahq.org/resources/coronavirus. (accessed 11/04/21)

33. Anesthesia Patient Safety Foundation (APSF). An update on perioperative considerations for the 2019 novel Coronavirus (COVID19). https://www.apsf.org/article/an-update-on-the-perioperativeconsiderations-for-covid-19-severe-acute-respiratory-syndromecoronavirus-2-sars-cov-2/ (accessed 11/04/21)

34. Clayton-Smith A, Bennett K, Alston RP, Adams G, Brown G, Hawthorne T, et al. A comparison of the efficacy and adverse effects of double-lumen endobronchial tubes and bronchial blockers in thoracic surgery: a systematic review and meta-analysis of randomized controlled trials. J Cardiothorac Vasc Anesth. 2015;29:955-66. https:// doi.org/10.1053/j.jvca.2014.11.017.34 A thorough systematic review and meta-analysis of randomized controlled trials that concluded that double-lumen tubes can be placed quicker and more reliably than bronchial blockers.

35. Narayanaswamy M, McRae K, Slinger P, Dugas G, Kanellakos GW, Roscoe A. Lacroix M Choosing a lung isolation device for thoracic surgery: a randomized trial of three bronchial blockers versus double-lumen tubes. Anesth Analg. 2009;108(4):1097101. https://doi.org/10.1213/ane.0b013e3181999339.

36. Fitzmaurice GJ, Ryan RJ, Young VK, Wall C, Dunne E, Dowd N, et al. Fanning $\mathrm{N}$ Thoracic surgical oncology: maintaining a highvolume surgical program during the COVID-19 pandemic. Ann Thorac Surg. 2020;110(5):e451-2. https://doi.org/10.1016/j. athoracsur.2020.05.017.

37. Misra S, Behera BK, Elayat A. Novel closed-loop bronchoscopy barrier sheath: valuable addition for one-lung ventilation during the coronavirus disease 2019 pandemic. J Cardiothorac Vasc Anesth. 2020;35(3):969-71. https://doi.org/10.1053/j.jvca.2020.06.070.

38. Ponnaiah V, Bailey CR. One-lung ventilation during the COVID19 pandemic. Anaesthesia. 2020;75(11):1546-7. https://doi.org/10. 1111/anae.15159.

39. Bellis M, Accardo R, Di Maio M, et al. Is flexible bronchoscopy necessary to confirm the position of double-lumen tubes before thoracic surgery? Eur J Cardiothorac Surg. 2011;40:912-8. https://doi.org/10.1016/j.ejcts.2011.01.070.

40. Thornton M, Reid D, Shelley B, Steven M. Management of the airway and lung isolation for thoracic surgery during the COVID19 pandemic: a reply. Anaesthesia. 2020;75(11):1548-9. https:// doi.org/10.1111/anae.15204.

41. Teleflex Rusch ${ }^{\circledR}$ EZ-Blocker ${ }^{\mathrm{TM}}$. Instructions for use. https:// www.teleflex.com/usa/en/product-areas/anesthesia/airway-management/endobronchial-blockers/ez-blocker-clinical-experience/ IFU-02771-001_00.pdf. (accessed 11/04/21)

42. Moritz A, Irouschek A, Birkholz T, Prottengeier J, Sirbu H, Schmidt J. The EZ-blocker for one-lung ventilation in patients undergoing thoracic surgery: clinical applications and experience in 100 cases in a routine clinical setting. J Cardiothorac Surg. 2018;13(1):77. https://doi.org/10.1186/s13019-018-0767-9.

43. Parab SY, Kumar P, Divatia JV, Sharma K. A prospective randomized controlled double-blind study comparing auscultation and lung ultrasonography in the assessment of DLT position in elective thoracic surgeries involving one lung ventilation at a tertiary care cancer institute. Korean J Anesthesiol. 2019;72(1):24-31. https://doi. org/10.4097/kja.d.17.00081.

44. Hu WC, Xu L, Zhang Q, Wei L, Zhang W. Point-of-care ultrasound versus auscultation in determining the position of double-lumen tube. Medicine (Baltimore). 2018;97(13):e9311. https://doi.org/ 10.1097/MD.0000000000009311.
45. Magharious P, Cvetkovic D, Weigel T. An innovative way to achieve safe lung deflation during one-lung ventilation in a potential coronavirus disease 2019 patient: a case report. AA Pract. 2020;14(7):e01244. https://doi.org/10.1213/XAA.0000000000001244.

46. Bellini R, Salandini MC, Cuttin S, Mauro S, Scarpazza P, Cotsoglou C. Spontaneous pneumothorax as unusual presenting symptom of COVID-19 pneumonia: surgical management and pathological findings. J Cardiothorac Surg. 2020;15(1):310. https://doi.org/10.1186/s13019-020-01343-4.

47. Van den Eynde J, De Groote S, Van Lerberghe R, et al. Cardiothoracic robotic assisted surgery in times of COVID-19. J Robot Surg. 2020;14(5):795-7. https://doi.org/10.1007/s11701020-01090-7.

48. Lohser J. Slinger P (2015) Lung injury after one-lung ventilation: a review of the pathophysiologic mechanisms affecting the ventilated and the collapsed lung. Anesth Analg. 2015;121(2):302-18. https:// doi.org/10.1213/ANE.0000000000000808.

49. Lee DK, Kim HK, Lee K, Choi YH, Lim SH, Kim H. Optimal respiratory rate for low-tidal volume and two-lung ventilation in thoracoscopic bleb resection. J Cardiothorac Vasc Anesth. 2015;29(4):972-6. https://doi.org/10.1053/j.jvca.2014.06.029.

50. Christopherson DA, Yao WC, Lu M, Vijayakumar R, Sedaghat AR. High-efficiency particulate air filters in the era of covid-19: function and efficacy. Otolaryngol Head Neck Surg. 2020;163(6): 1153-5. https://doi.org/10.1177/0194599820941838.

51. GE Healthcare. HMEF and Filters. https://www.gehealthcare.co. uk/-/jssmedia/5c1e91befea54768a586c191e2e3a9ff.pdf?la=en-gb (accessed 11/04/21)

52. Anesthesia Patient Safety Foundation. https://www.apsf.org/faqon-anesthesia-machine-use-protection-and-decontamination-during-the-covid-19-pandemic. (accessed 11/04/21)

53. Society for Cardiothoracic Surgery. Theatre COVID pathway guidance. https://scts.org/wp-content/uploads/2020/03/SCTSACTACC-SCPS-Theatre-COVID-pathway-Final.pdf (accessed $11 / 04 / 21)$

54. Hargrave JM, Diehl RA, Holler KL, Gohar MAE. Adaptation allowing for bronchial blocker proximal port filtration during lung isolation for patients with airborne precautions. Anesthesiology. 2020;133(5):11189. https://doi.org/10.1097/ALN.0000000000003552.

55. Mustaev M, Bille A, Hasan M, et al. Simulation and measurement of aerosolisation in different chest drainage systems. Semin Thorac Cardiovasc Surg. 2020;S1043-0679(20):30347-30346. https://doi. org/10.1053/j.semtcvs.2020.10.002.

56. Hallifax R, Wrightson J, Bibby A, et al. Pleural services during COVID-19 pandemic, 2020. Available: https://www.brit-thoracic. org.uk/document-library/quality-improvement/covid-19/pleuralservices-during-covid-19-pandemic/ (accessed 11/05/21)

57. Duffy C, Kidd A, Francis S, Tsim S, McNaughton L, Ferguson K, et al. Chest drain aerosol generation in COVID-19 and emission reduction using a simple anti-viral filter. BMJ Open Respir Res. 2020;7(1):e000710. https://doi.org/10.1136/bmjresp-2020-000710.

58. Ahmed H, Patel K, Greenwood DC, et al. Long-term clinical outcomes in survivors of severe acute respiratory syndrome and Middle East respiratory syndrome coronavirus outbreaks after hospitalisation or ICU admission: a systematic review and meta-analysis. J Rehabil Med. 2020;52(5):jrm00063. https://doi.org/10.2340/16501977-2694.

59. Zhao YM, Shang YM, Song WB, Li QQ, Xie H, Xu QF, et al. Followup study of the pulmonary function and related physiological characteristics of COVID-19 survivors three months after recovery. EClinicalMedicine. 2020;25:100463. https://doi.org/10.1016/j.eclinm. 2020.100463.

Publisher's Note Springer Nature remains neutral with regard to jurisdictional claims in published maps and institutional affiliations. 